\title{
Sistem Edukasi Pengenalan Waktu pada Anak Usia Dini Berbasis Multimedia di Taman Kanak-Kanak Bustanul Athfal Medan
}

\author{
Address : Universitas Harapan Medan \\ Email: dvgimunte@gmail.com \\ Correspondence : dvgimunte@gmail.com
}

\author{
David
}

\begin{abstract}
Abstrak
Pengenalan waktu sangat penting untuk diketahui oleh manusia. Pada zaman dahulu manusia mengenali waktu berdasarkan tanda-tanda alami yang ditunjukan oleh alam. Saat ini manusia mengetahui waktu dengan mempergunakan jam. Pengenalan waktu ini diajarkan pada anak-anak sejak dini melalui berbagai cara, antara lain dengan alat peraga. Adapun cara yang penulis ajukan adalah dengan mempergunakan media interaktif berupa permainan dimana cara ini lebih atraktif dibandingkan dengan metode konvesional. Sebelumnya diharapkan dengan adanya aplikasi ini siswa/siswi TK Bustanul Athfal Medan dapat mengenali waktu dengan benar.
\end{abstract}

Kata Kunci : Aplikasi, Game/permainan, Edukasi, Multimedia.

\section{Latar Belakang}

Perkembangan teknologi saat ini sangat pesat, terutama dalam bidang komputer kecanggihan teknologi saat ini dapat mengkualifikasikan perangkat diluar komputer, dan disimulasikan kedalam komputer dalam bentuk Visual.

Citra game (Permainan) dimasyarakat masih dipandang sebagai media yang menghibur dibanding sebagai media pembelajaran. Sifat dasar game yang menantang (Challenging), membuat ketagihan (Addicted) dan menyenangkan (Fun) bagi mereka yang menyukai permainan modern ini dapat berdampak negatif apabila yang dimainkan adalah game yang tidak bersifat edukasional. Untuk itu perlu dikembangkan sebuah game edukasi yang dapat digunakan sebagai media pembelajaran yang dapat memotivasi siswa agar tertarik dalam belajar.

Game tidak pernah mengenal umur dan status dalam masyarakat, semua kalangan dapat menikmati game, tua-muda, kaya-miskin, maupun pria-wanita, semua dapat menikmati game. Dan game selalu bisa menghibur semua kalangan. Selain menghibur game juga mampu memberikan dampak negatif lainnya, salah satunya kecanduan sehingga membuat orang yang memainkannya malas untuk melakukan aktifitas lainnya. Kini di zaman modern banyak sekali media untuk bermain game. Ada Smartphone (telepon pintar), tab (tablet/gadget), Game Portable (PSP) dan Game Machine (Game PC) lainnya. 
Games sebenarnya penting dalam perkembangan otak, untuk meningkatkan konsentrasi dan melatih untuk memecahkan masalah dengan tepat dan cepat karena dalam game terdapat berbagai konflik atau masalah yang menuntut kita untuk menyelesaikannya dengan cepat dan tepat.

Seiring dengan perkembangan zaman, ditemukan teknologi yang dapat memberikan manfaat dalam membantu proses belajar mengajar. Salah satunya adalah menggunakan aplikasi multimedia, yang dapat membuat pelajaran menjadi lebih aktratif dan efektif

Secara umum proses pendidikan formal di Indonesia dimulai dari Pendidikan Anak usia dini (PAUD) dan dapat juga dari Taman KanakKanak. Dalam proses ini anak - anak diperkenalkan dengan konsep - konsep dasar belajar, termasuk pengenalan waktu.

Pada TK Bustanul Athfal pengenalan anak dilakukan dengan memperlihatkan gambar dan tulisan. Bagi sebahagian anak cara ini terkadang kurang menarik dan membosankan. Untuk itu penulis membuat suatu game edukasi yang dapat menarik minat anak-anak dalam mengenal waktu. Adapun game edukasi tersebut penulis tuangkan dalam bentuk Tugas Akhir dengan judul "Sistem Edukasi Pengenalan Waktu Pada Anak Usia Dini Berbasis Multimedia Di Taman Kanak-Kanak Bustanul Athfal Medan.

\section{METODE}

Metode penelitian adalah metode dari pengumpulan data yang dilakukan oleh penulis dalam mendapatkan informasi yang mendukung dalam penulisan Tugas Akhir. Adapun teknik pencairan fakta yang penulis pergunakan adalah:

\section{a. Wawancara}

Metode wawancara dilakukan dengan mengadakan tanya jawab langsung dengan pihak-pihak yang mengetahui tentang cara pengenalan waktu kepada siswa/siswi Taman Kanak-Kanak (TK).

b. Observasi

Observasi dilakukan dengan cara melakukan pengamatan langsung terhadap objek yang diteliti.

\section{c. Studi Pustaka}

Metode studi pustaka dilakukan dengan mengumpulkan beberapa informasi yang terdapat pada jurnal, buku dan internet

\section{HASIL}

\subsection{Perancangan Struktur Menu}

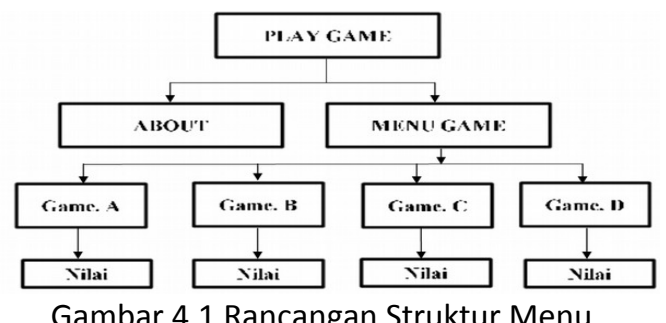

Rancangan Struktur Menu dari awal masuk ke Menu Utama sampai dengan pemberian nilai dari setiap game yang dipilih. Ketika formulir play game dipilih, maka user akan pindah ke form menu yaitu About dan Menu Game, Menu About akan menampilkan form biodata penulis dan Menu Game akan menampilkan pilihan dari game. Setiap game yang akan dipilih memiliki nilai yang akan muncul di akhir soal yang diberikan.

\subsection{Rancangan Halaman Utama}

Pada halaman ini menampilkan teks, logo dan tombol mulai, rancangan halaman menu dapat dilihat pada gambar 4.2.

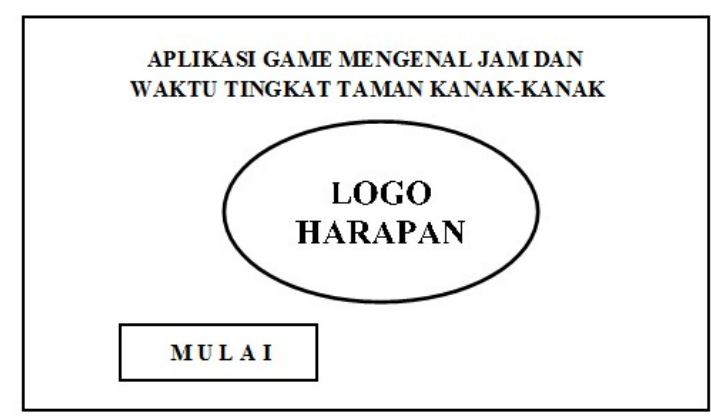

Gambar 4.2. Rancangan Halaman Utama 


\subsection{Rancangan Halaman Menu Game}

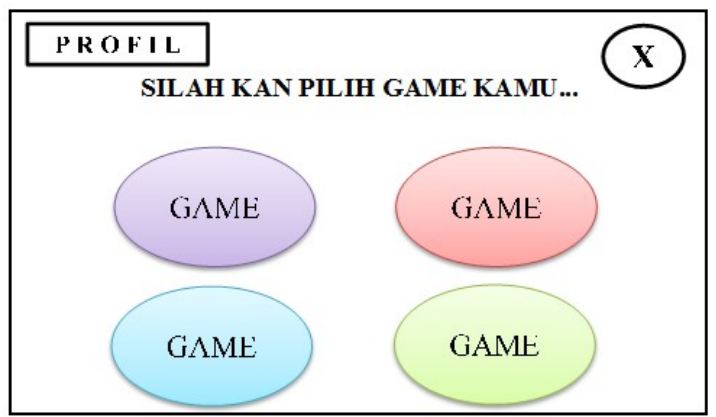

Gambar 4.3 Rancangan Halaman Menu Game

Terdapat empat buah pilihan, dimana pilihan game tersebut berbeda satu sama lainnya. Tombol $\mathrm{X}$ berfungsi keluar dari aplikasi. Tombol profil berfungsi sebagai tombol navigasi langsung ke Menu About. Rancangan halaman Menu Game dapat dilihat pada gambar 4.3.

\subsection{Rancangan Game A}

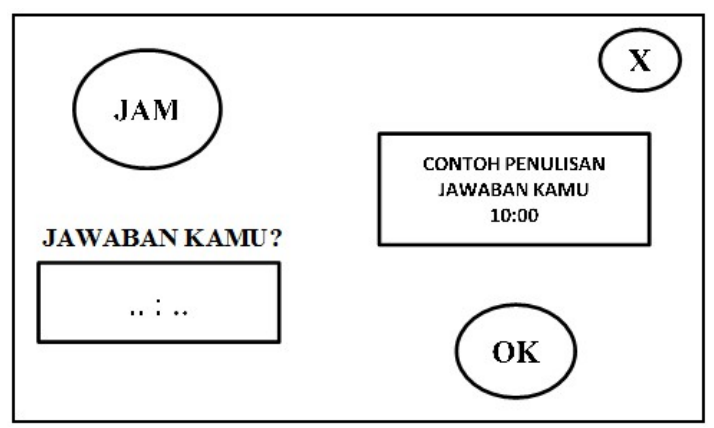

Gambar 4.4 Rancangan Game A

Pada gambar Rancangan Game A menunjukan pada form gambar jam menampilkan waktu dimana user harus menjawabnya dengan benar, serta megisi dikolom "Jawaban Kamu" namun user harus meng klik bagian kolom tersebut agar dapat menjawabnya. Syarat penulisan jawabannya ada pada contoh penulisannya. Ketika user telah menjawab, maka user harus klik "oke" agar game berlanjut ke soal berikutnya.

\subsection{Rancangan Game B}

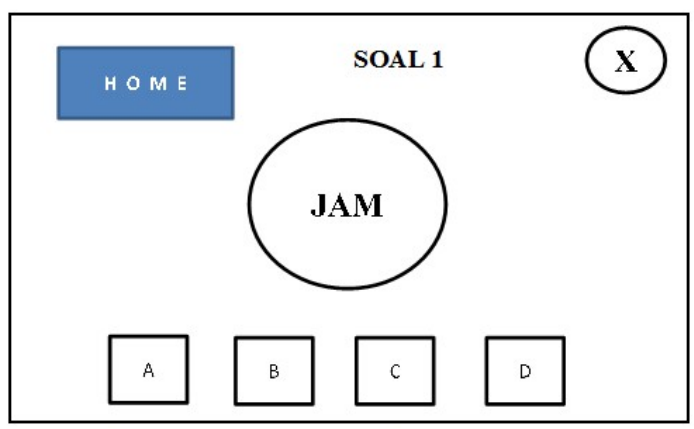

Gambar 4.5 Rancangan Game B

Pada gambar Rancangan Game B menunjukkan gambar jam, dan user harus menjawabnya dengan memilih " $a, b, c$ atau d yang benar. Tombol out pada form diatas berfungsi keluar dari aplikasi game. Dan tombol home berfungsi sebagai kembali ke menu pilih game.

\subsection{Rancangan Game C}

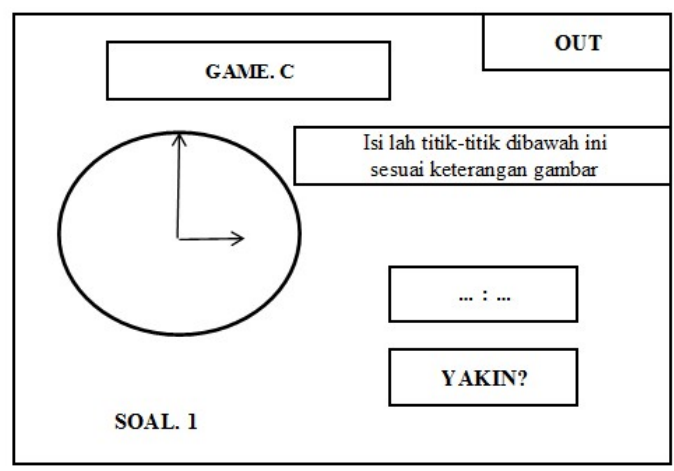

Gambar 4.6 Rancangan Game C

Pada gambar Rancangan Game C menunjukkan user harus menjawab pertanyaan yang beracuan kepada gambar jam dengan mengisi titik-titik yang berada di dalam kotak setelah menjawab user harus mengklik tombol yakin. Tombol out pada form diatas berfungsi sebagai mengembalikan ke menu game.

\subsection{Rancangan Game D}

Pada Gambar 4.7. Rancangan Game D meunjukkan user harus menyesuaikan gambar jam diatas dengan tombol jam angka dengan cara menarik tombol tersebut kearah jam yang berada diaatas. Tombol out pada form diatas 
berfungsi sebagai mengembalikan ke menu game.

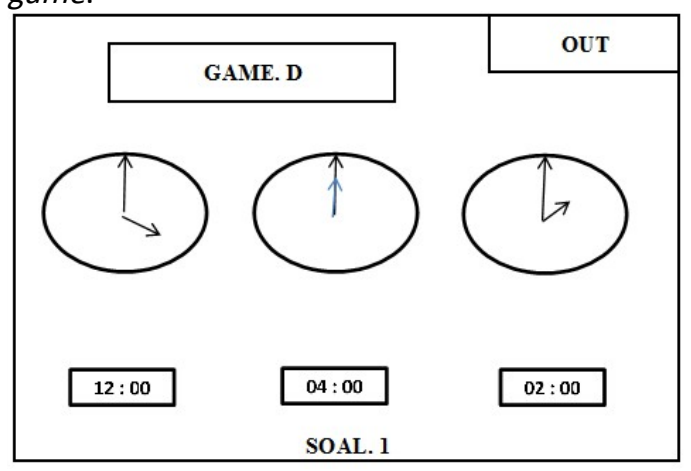

Gambar 4.7 Rancangan Game D

\subsection{Rancangan Menu About}

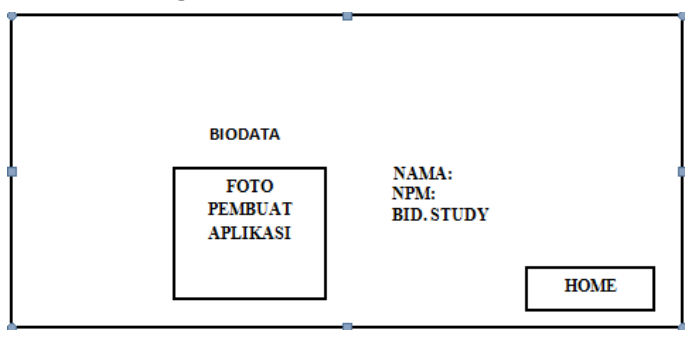

Gambar 4.8 Rancangan Menu About

Merupakan Menu yang berfungsi untuk menampilkan biodata singkat penulis. Disamping itu terdapat sebuah tombol "Home" yang berfungsi untuk mengembalikan pengguna aplikasi ke Menu Game.]

\subsection{Pembahasan Aplikasi}

Pada gambar 5.1. Implementasi program adalah suatu gambaran bagaimana bentuk dan cara penggunaan program yang dibuat agar pengguna dapat mengerti menggunakan program yang dibuat. Tampilan hasil implementasi aplikasi Game ini adalah sebagai berikut:

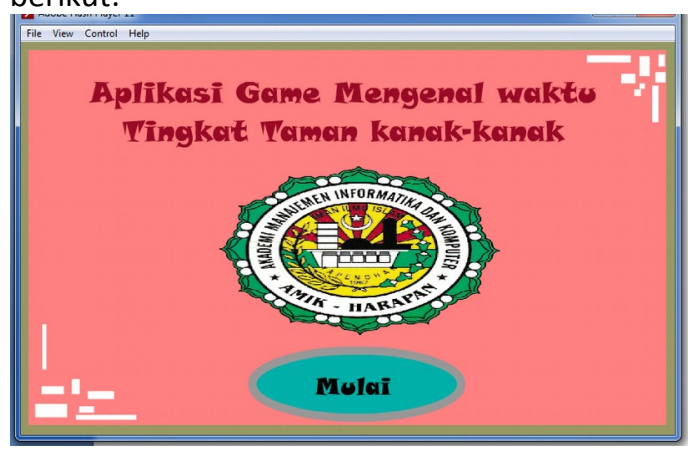

Program Studi Teknik informatika

Universitas Prima Indonesia (UNPRI) Medan

\section{Gambar 5.1 Tampilan Menu Utama}

Pada gambar 5.1. Tampilan diatas merupakan awal program saat dijalankan, pengguna harus klik tombol Mulai agar dapat masuk ke Menu utama sehingga pengguna dapat memulai Aplikasi Game Mengenal Jam Dan Waktu Tingkat taman kanak-kanak.

\subsection{Tampilan Menu Game}

Setelah masuk aplikasi dari tombol mulai tampilan utama, maka akan masuk ke menu utama dimana dimenu utama ini terdapat beberapa pilihan game serta profil singkat dari biodata pembuat.

Pada gambar 5.2. halaman menu utama diatas pengguna dapat memilih beberapa menu ada 4 menu pilihan, yaitu: Game Guess, Game Selection, Game Match, Game Multiple Choice, dan tombol $\mathrm{X}$ untuk keluar dari aplikasi.

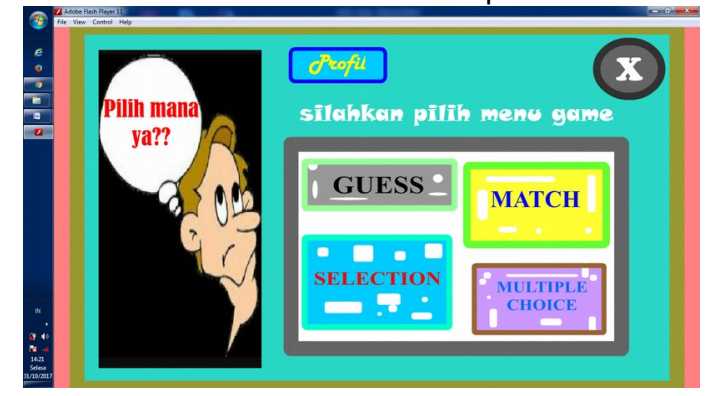

Gambar 5.2 Tampilan Menu Game

\section{Tampilan Game Guess}

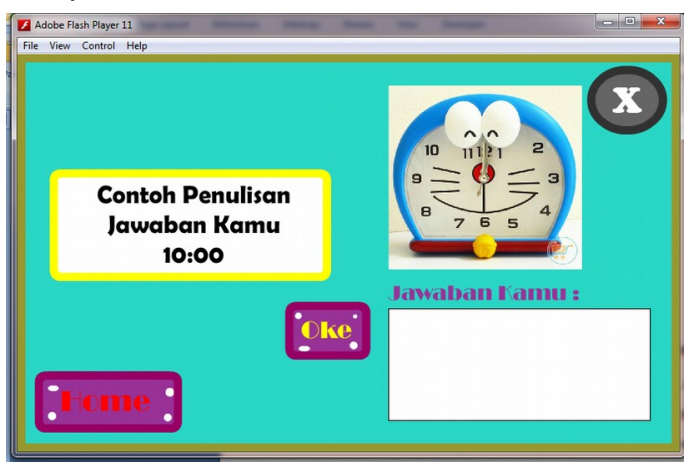

Gambar 5.3 Tampilan Game Guess

Pada gambar 5.3. Tampilan diatas merupakan halaman game guess yang menampilkan gambar sebagai soal dan jawaban kamu adalah tempat untuk menjawab soal gambar. Dan memiliki keterangan cara penulisan untuk menjawab soal gambar. 
Pengguna tinggal mengklik kolom kosong dan menulis jawaban sesuai dengan tata cara penulisan jawaban serta menjawab soal gambar dengan benar, setelah menjawab maka pengguna harus menekan tombol OKE untuk melanjutkan soal berikutnya. Pada Game Tebak terdiri dari 10 soal. Disitu ada tombol HOME untuk kembali ke menu utama, tombol PLAY AGAIN untuk bermain kembali / lanjut bermain dan tombol $\boldsymbol{X}$ untuk keluar. Setelah selesai bermain Game Tebak hingga 10 soal, maka muncul lah layar jawaban, layar jawaban tersebut berisi tentang hasil nilai permainan benar dan salah pada pengguna tadi.

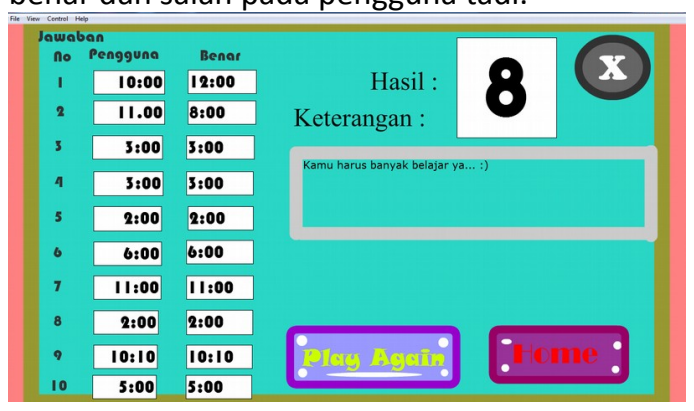

Gambar 5.4 Tampilan Jawaban

\section{Tampilan Game Selection}

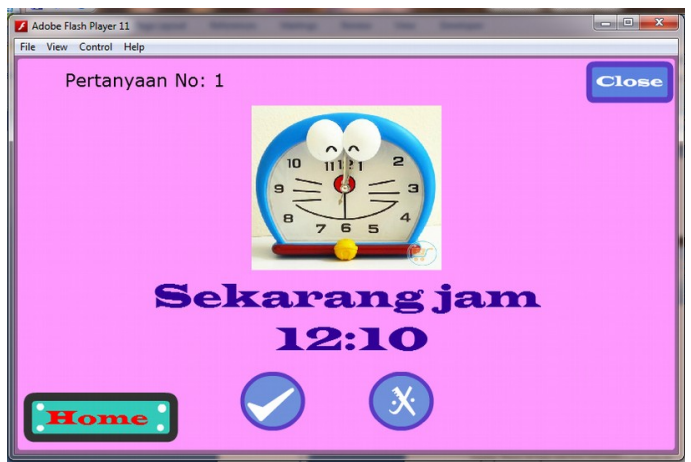

Gambar 5.5. Tampilan Game Selection

Pada gambar 5.5. Merupakan tampilan halaman game Selection, untuk mejawab pertanyaan gambar diatas pengguna dituntut untuk meyakinkan jawaban Benar atau Salah. Pernyataan soal diatas tidak selalu benar, maka pengguna harus benar-benar teliti dalam menjawab pertanyaan. Ada bagian tombol home untuk kembali ke menu utama dan tombol close untuk keluar. Setelah selesai menyelesaikan 1 soal Game Selection, maka muncul lah layar hasil, layar hasil tersebut berisi tentang hasil nilai permainan benar dan salah pada pengguna tadi.

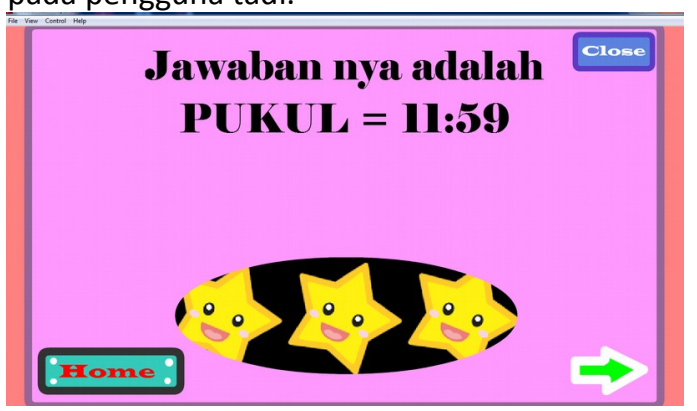

Gambar 5.6 Tampilan Hasil

Tampilan Game Match

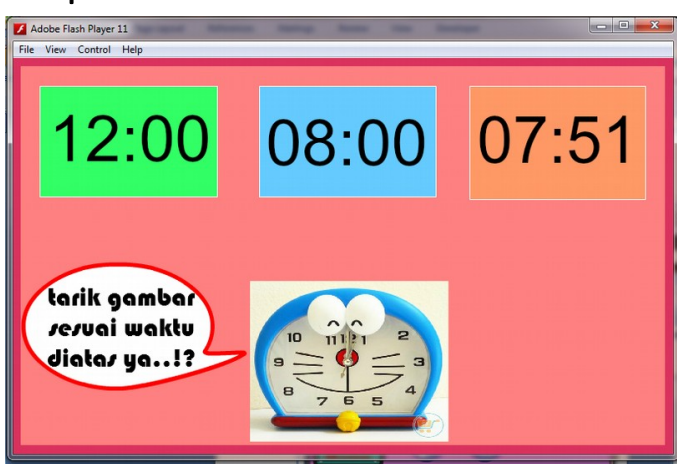

Gambar 5.7 Tampilan Game Match

Pada gambar 5.7. Merupakan tampilan halaman game Match, pada game ini pengguna menjawab pertanyaan gambar dengan cara menarik gambar ke angka jam yang berada diatas gambar, pengguna harus menyesuaikan gambar dengan angka agar mendapatkan point. Setelah selesai bermain Game Match hingga beberapa soal, maka muncul lah layar jawaban, layar jawaban tersebut berisi tentang hasil nilai permainan benar dan salah pada pengguna tadi.

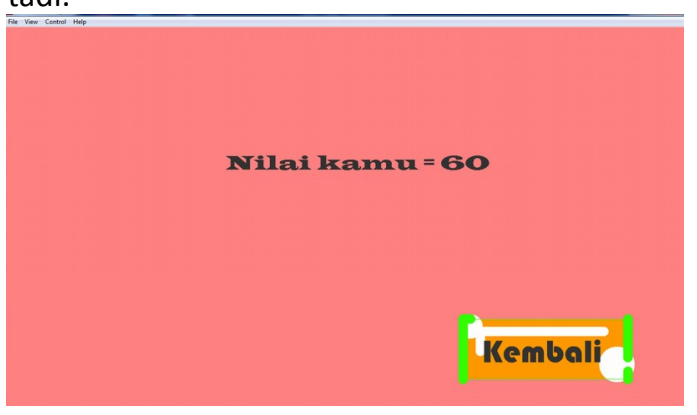

Gambar 5.8 Tampilan Jawaban 
Tampilan Game Multiple Choice

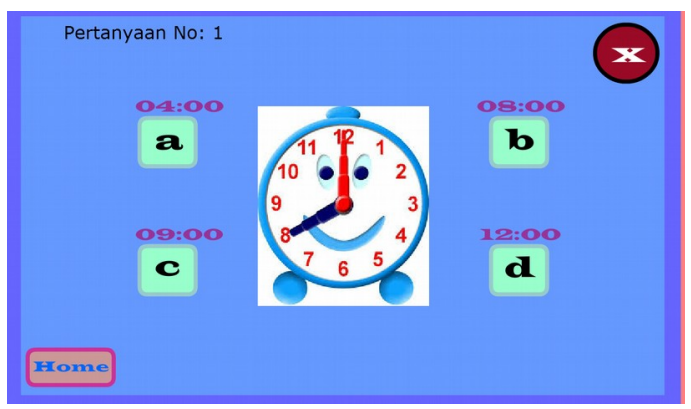

Gambar 5.9 Tampilan Multiple Choice

Pada gambar 5.9. Tampilan diatas menunjukkan halaman game dimana pengguna harus menjawab dengan benar berdasarkan soal gambar dan harus memilih jawaban yang benar dengan mengklik tombol a, b, c, atau d. Ada bagian tombol home untuk kembali ke menu utama dan tombol $X$ untuk keluar. Setelah selesai menyelesaikan 1 soal Game Multiple Choice, maka muncul lah layar hasil, layar hasil tersebut berisi tentang hasil nilai permainan benar dan salah pada pengguna tadi.

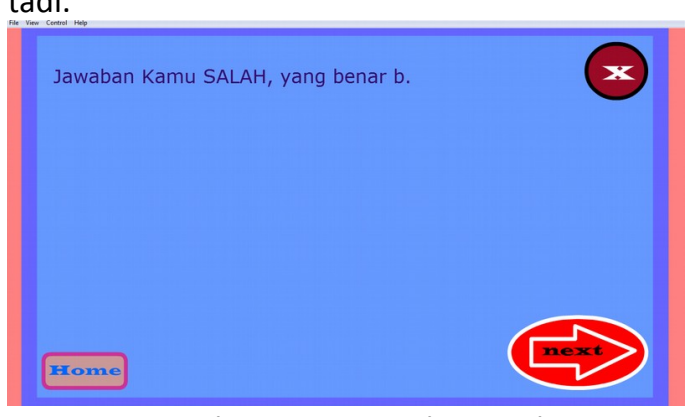

Gambar 5.10 Tampilan Hasil

\section{KESIMPULAN DAN SARAN}

\subsection{Kesimpulan}

Beberapa kesimpulan yang dapat diambil dari tugas Akhir ini adalah aplikasi ini telah berhasil berjalandengan baik pada komputer atau laptop dengan menggunakan Software Adobe Flash Cs6 dan ActionScript 3 yang digunakan sebagai bahasa pemograman dari aplikasi yang telah dibuat. Dengan adanya Aplikasi Game edukasi Pengenalan Waktu Pada Taman Kanak-Kanak Bustanul Athfal Medan ini dapat membantu mempermudah proses belajar mengajar. Aplikasi ini dibuat dengan tujuan memberikan kemudahan bagi siswa/siswi mengenal waktu dan jam, tanpa lagi belajar menggunakan buku, karena aplikasi ini berjalan pada komputer atau laptop, sehingga siswa/siswi dapat belajar dan menggunakannya dimana saja.

\subsection{Saran}

Terdapat beberapa saran bagi penulis, sehingga pembaca atau penulis lain dapat memahami apa saja kekurangan yang harus diselesaikan permasalahannya, sehingga aplikasi dapat dikembangkan lebih baik lagi: Agar penggunaan aplikasi lebih optimal, aplikasi ini hanya dijalankan di komputer atau leptop saja. Untuk mendapatkan akses atau pemakaian yang lebih praktis lagi penulis lain dapat mengembangkan aplikasi ini untuk diaplikasikan ke smartphone android. Aplikasi ini mempunyai konten gambar animasi waktu dan jam yang diambil melalui internet,untuk menghasilkan aplikasi lebih baik lagi, seharusnya pengambilan data selain internet dikurangi seperti gambar waktu dan jam yang diambil melalui internet, dapat diganti dengan gambar waktu dan jam yang memang buatan sendiri.

\section{DAFTAR PUSTAKA}

Arif, Ridwan. 2009. Jurnal Algoritma. Sekolah Tinggi Teknologi Jayaraga Garut. Garut.

Daryanto. 2013. Media Pembelajaran: Peranannya Sangat Penting Dalam Mencapai Tujuan Pembelajaran. Gava Media. Yogyakarta

Kadir, Abdul. 2003. Pemograman Web mencakup : HTML,CSS, JavaScript \& PHP. Andi. Yogyakarta.

Sadiman, A. S., Raharjo., Anung H., dan Rahardjito. 2010. Media Pendidikan: Pengertian, Pengembangan, dan Pemanfaatannya. Raja Grafindo Persada. Jakarta

Sanjaya, Rangga. 2016. Jurnal Informatika. Universitas Bina Sarana Informatika. Bandung. 
Sari, Yuli Purnama. 2009. Media Pembelajaran. Rajawali Pers. Palembang

Yasin, Sulchan. 1997. Kamus Pintar Bahasa Indonesia. Amanah. Surabaya.

Kotler, Phillip. 1997. Manajemen Pemasaran Analisis, Perencanaan dan Implementasi. Prehalindo. Jakarta

Kismono, Gugup, Pengantar Bisnis, Edisi I, Cetakan I, BPFE, Yogyakarta, 2001.

http://nining.dosen.narotama.ac.id/ 2012/02/06/pengertian-multimediainteraktif//. Diakses pada tanggal 20 Oktober Pukul 23.35 Wib

http://id.wikipedia.org/wiki/ Perangkat lunak aplikasi. Diakses pada tanggal 20 Oktober Pukul 23.58 Wib 